\title{
Dimerization of Neuronal Calcium Sensor Proteins
}

\author{
James B. Ames* \\ Department of Chemistry, University of California, Davis, Davis, CA, United States
}

Neuronal calcium sensor (NCS) proteins are EF-hand containing $\mathrm{Ca}^{2+}$ binding proteins that regulate sensory signal transduction. Many NCS proteins (recoverin, GCAPs, neurocalcin and visinin-like protein 1 (VILIP1)) form functional dimers under physiological conditions. The dimeric NCS proteins have similar amino acid sequences (50\% homology) but each bind to and regulate very different physiological targets. Retinal recoverin binds to rhodopsin kinase and promotes $\mathrm{Ca}^{2+}$-dependent desensitization of light-excited rhodopsin during visual phototransduction. The guanylyl cyclase activating proteins (GCAP1-5) each bind and activate retinal guanylyl cyclases (RetGCs) in lightadapted photoreceptors. VILIP1 binds to membrane targets that modulate neuronal secretion. Here, I review atomic-level structures of dimeric forms of recoverin, GCAPs and VILIP1. The distinct dimeric structures in each case suggest that NCS dimerization may play a role in modulating specific target recognition. The dimerization of recoverin and VILIP1 is $\mathrm{Ca}^{2+}$-dependent and enhances their membrane-targeting $\mathrm{Ca}^{2+}$-myristoyl switch function. The dimerization of GCAP1 and GCAP2 facilitate their binding to dimeric RetGCs and may allosterically control the $\mathrm{Ca}^{2+}$-dependent activation of RetGCs.

Keywords: calcium, dimer, GCAP1, GCAP2, GCAP5, recoverin, VILIP1, NCS protein

\section{OPEN ACCESS}

Edited by:

Daniele Dell'Orco,

Università degli Studi di Verona, Italy

Reviewed by:

Eugene Anatolievich Permyakov, Institute for Biological Instrumentation

(RAS), Russia

Rameshwar K. Sharma, Salus University, United States

*Correspondence: James B. Ames jbames@ucdavis.edu

Received: 31 August 2018 Accepted: 11 October 2018 Published: 02 November 2018

Citation:

Ames JB (2018) Dimerization of Neuronal Calcium Sensor Proteins. Front. Mol. Neurosci. 11:397. doi: 10.3389/fnmol.2018.00397

\section{INTRODUCTION}

Intracellular calcium ion $\left(\mathrm{Ca}^{2+}\right)$ is a second messenger in the brain and retina that modulates sensory signal transduction processes (Berridge et al., 2000; Augustine et al., 2003). Sensory stimuli cause changes in cytosolic $\mathrm{Ca}^{2+}$ levels that are detected by a family of $\mathrm{Ca}^{2+}$-binding proteins called, neuronal calcium sensor (NCS) proteins (Ames et al., 1996; Braunewell and Gundelfinger, 1999; Burgoyne and Weiss, 2001; Burgoyne et al., 2004; Weiss et al., 2010; Ames and Lim, 2012). More than 20 different NCS proteins have been identified so far (Weiss and Burgoyne, 2002; Haynes et al., 2012), including recoverin (Dizhoor et al., 1991) and guanylyl cyclase activating proteins (GCAP1-5; Dizhoor et al., 1994; Palczewski et al., 1994) that regulate visual phototransduction in retinal photoreceptor cells (Palczewski et al., 2000; Ames and Ikura, 2002; Stephen et al., 2008; Ames and Lim, 2012). NCS homologs are also expressed in the brain and spinal cord, such as neurocalcin (Hidaka and Okazaki, 1993), frequenin (NCS-1; Pongs et al., 1993; McFerran et al., 1998), visinin-like proteins (VILIPs; Bernstein et al., 1999; Braunewell and Klein-Szanto, 2009) and hippocalcin (Kobayashi et al., 1992, 1993; Tzingounis et al., 2007).

Recoverin (Dizhoor et al., 1991; Kawamura and Murakami, 1991) is expressed exclusively in retinal rod and cone cells, where it promotes the desensitization of light-excited rhodopsin (Kawamura, 1993; Erickson et al., 1998; Makino et al., 2004) by inhibiting rhodopsin kinase activity in dark-adapted photoreceptors (Calvert et al., 1995; Chen et al., 1995; Klenchin et al., 1995; Komolov et al., 2009). The $\mathrm{Ca}^{2+}$-bound form of recoverin forms a dimer in solution 
(Myers et al., 2013) that binds to rhodopsin kinase (Chen et al., 1995; Klenchin et al., 1995). Recoverin dimerization has been suggested to facilitate the binding of rhodopsin kinase with dimeric rhodopsin (Myers et al., 2013). Recoverin dimerization may also regulate light-dependent activation of phosphodiesterase (Chen et al., 2012) and light-induced disulfide dimerization at Cys39 (Permyakov et al., 2007, 2012; Zernii et al., 2015). Lastly, recoverin appears to have alternative functions in the rod inner segment (Strissel et al., 2005) that are implicated in cancer-associated retinopathy (Polans et al., 1991; Subramanian and Polans, 2004).

GCAP1-5 bind to and activate retinal guanylyl cyclases (RetGCs1 and RetGC2; Dizhoor et al., 1994; Palczewski et al., 1994, 2004). The GCAP1-modulated RetGC1 transduction system also exists in the olfactory bulb (Duda et al., 2001). GCAP1, GCAP2 and GCAP5 each form a dimer in solution (Ermilov et al., 2001; Lim et al., 2017, 2018) that binds to dimeric RetGC1 (Liu et al., 1997; Ramamurthy et al., 2001). The GCAPs activate RetGCs at low $\mathrm{Ca}^{2+}$ levels in light activated photoreceptors (Peshenko and Dizhoor, 2006; Lim et al., 2009), whereas $\mathrm{Ca}^{2+}$-bound GCAPs inhibit RetGCs at high $\mathrm{Ca}^{2+}$ levels in dark-adapted photoreceptors (Dizhoor and Hurley, 1996; Dizhoor et al., 1998). Surprisingly, $\mathrm{Ca}^{2+}$-bound GCAP1 can stimulate the odorant surface receptor ONE-GC (Duda et al., 2012a), which raises the question about how GCAP1 dimeric sites can recognize two different target sites existing in RetGC1 and
ONE-GC. The $\mathrm{Ca}^{2+}$ sensitive activation of RetGCs by GCAPs in the retina promotes the recovery phase of visual excitation, and particular GCAP1 mutants that disrupt the cyclase activation are linked to retinal degenerative diseases (Semple-Rowland et al., 1996; Sokal et al., 1998; Baehr and Palczewski, 2007; Bondarenko et al., 2010; Jiang and Baehr, 2010).

The VILIP1-3; (Braunewell and Klein-Szanto, 2009) are dimeric NCS proteins (Li et al., 2009) that are expressed exclusively in the brain and spinal cord. VILIP1 is localized primarily in the rat hippocampus (Paterlini et al., 2000; Zhao and Braunewell, 2008), where it controls neuronal excitability important for learning and memory (Braunewell et al., 2003; Brackmann et al., 2004). In particular, VILIP1 binds to the $\alpha$-subunit of the $\alpha_{4} \beta_{2}$ nicotinic acetylcholine receptor (nAChR), which promotes its surface expression and trafficking in oocytes (Lin et al., 2002) and hippocampal neurons (Zhao et al., 2009b). The $\mathrm{Ca}^{2+}$-induced surface expression of $\mathrm{nAChR}$ promoted by VILIP1 therefore modulates neuronal excitability in hippocampal neurons (Gierke et al., 2008; Zhao et al., 2009a,b) and regulates synaptic plasticity (Braunewell, 2005; Braunewell and Klein-Szanto, 2009).

All NCS proteins contain four EF-hand $\mathrm{Ca}^{2+}$-binding motifs (Moncrief et al., 1990; Ikura, 1996), a covalently attached $\mathrm{N}$-terminal myristoyl group, and conserved amino acid residues in the EF-hand motifs, particularly in the $\mathrm{Ca}^{2+}$-binding loops (Figure 1). The first EF-hand (EF1) contains a Cys followed by

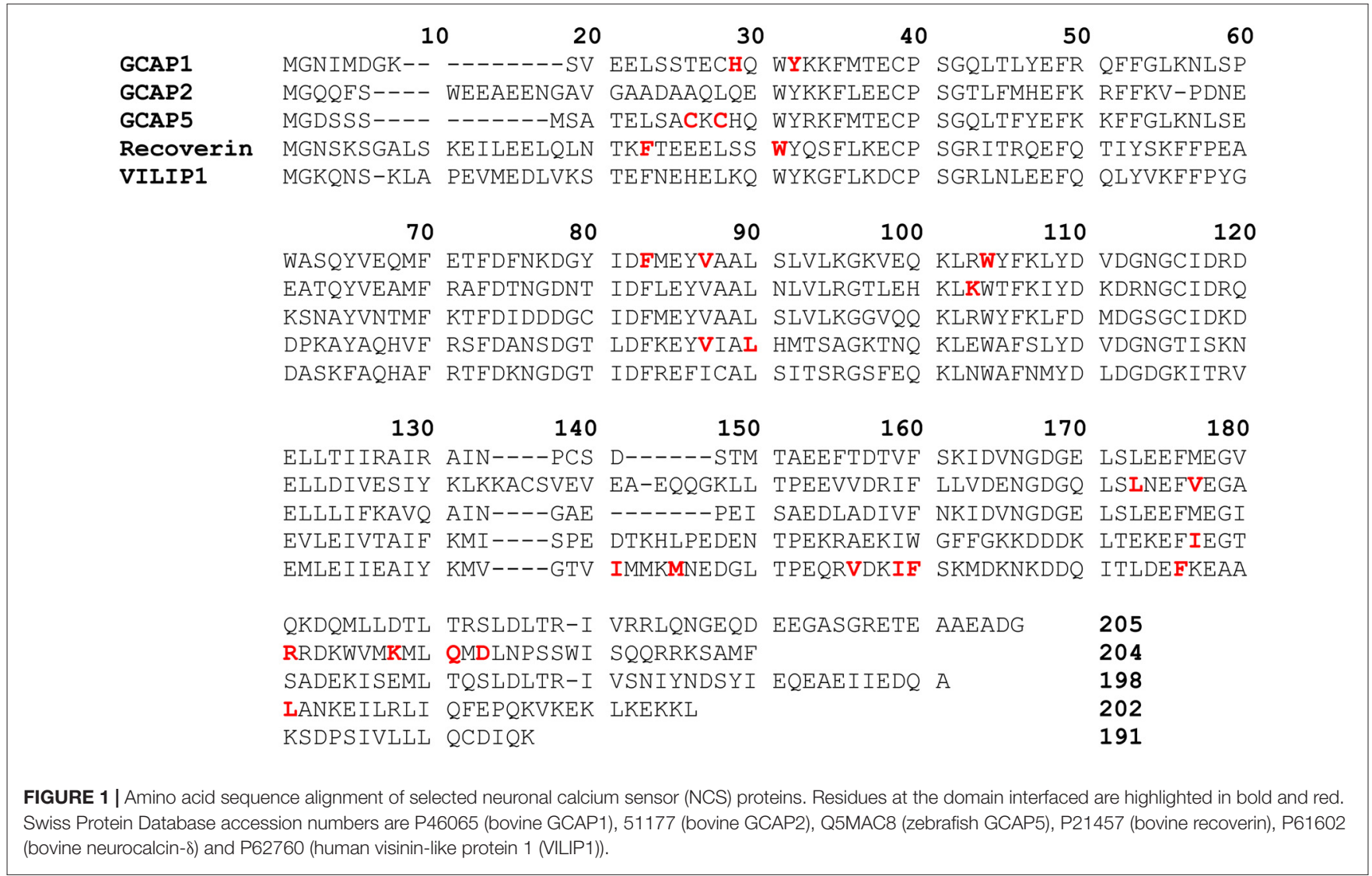


Pro in the binding loop that disables $\mathrm{Ca}^{2+}$ binding at this site in all NCS proteins. The second and third EF-hands (EF2 and EF3) both bind $\mathrm{Ca}^{2+}$ with high affinity (Cox et al., 1994; Ames et al., 1995). The fourth EF-hand sequence is variable, and $\mathrm{Ca}^{2+}$ is able to bind to EF4 in neurocalcin- $\delta$ (Ladant, 1995) and GCAPs (Peshenko and Dizhoor, 2007; Stephen et al., 2007) but $\mathrm{Ca}^{2+}$ does not bind to EF4 in recoverin (Ames et al., 1995) and VILIPs (Cox et al., 1994; Li et al., 2011). $\mathrm{Ca}^{2+}$-binding to EF4 in GCAP1 controls whether GCAP1 can activate or inhibit guanylyl cyclase (Peshenko and Dizhoor, 2007). Residues outside the EF-hand motifs are generally not conserved and may play a role in target recognition (Zernii et al., 2011).

N-terminal myristoylation anchors some NCS proteins to cellular membranes by a mechanism termed, $\mathrm{Ca}^{2+}$-myristoyl switch (Dizhoor et al., 1992; Kobayashi et al., 1993; Ladant, 1995). Myristoylated recoverin binds to retinal disc membranes at high $\mathrm{Ca}^{2+}$ levels in dark-adapted photoreceptors (Zozulya and Stryer, 1992; Dizhoor et al., 1993; Dell'Orco et al., 2012), whereas unmyristoylated recoverin is localized in the cytosol (Zozulya and Stryer, 1992; Dizhoor et al., 1993). Likewise, myristoylated forms of neurocalcin (Ladant, 1995), hippocalcin (Kobayashi et al., 1993) and VILIPs (Li et al., 2011) each exhibit $\mathrm{Ca}^{2+}$. induced localization at the plasma membrane in neurons. The attached fatty acyl group interacts quite differently with each NCS protein as seen in the structures for $\mathrm{Ca}^{2+}$-free recoverin (Tanaka et al., 1995), NCS1 (Lim et al., 2011), GCAP1 (Lim et al., 2016) and VILIP3 (Li et al., 2016). Thus, N-terminal myristoylation serves to fine tune the tertiary structure of each NCS protein in a unique way to promote functional diversity (Ames and Lim, 2012). Recoverin's $\mathrm{Ca}^{2+}$-myristoyl switch may control its light-induced movement into the rod inner segment (Strissel et al., 2005). GCAP proteins are also myristoylated
(Palczewski et al., 1994; Frins et al., 1996; Olshevskaya et al., 1997), but do not possess a functional $\mathrm{Ca}^{2+}$-myristoyl switch (Olshevskaya et al., 1997; Hwang and Koch, 2002). Instead the N-terminal myristoyl group remains sequestered inside GCAP1 in both $\mathrm{Ca}^{2+}$-free and $\mathrm{Ca}^{2+}$-bound states (Hughes et al., 1998; Lim et al., 2009) as demonstrated in the crystal structure of $\mathrm{Ca}^{2+}$-bound GCAP1 (Stephen et al., 2007) and NMR structure of the $\mathrm{Ca}^{2+}$-free activator state (Lim et al., 2016).

In this review article, I discuss the recent atomic-resolution structures of dimeric forms of recoverin (Myers et al., 2013), GCAP1 (Lim et al., 2018), GCAP2 (Pettelkau et al., 2012), GCAP5 (Lim et al., 2017) and VILIP1 (Li et al., 2011) that each adopt very different quaternary structures (Figure 2). While the tertiary structures of each monomeric subunit are somewhat similar, the distinct quaternary structures and unique subunit packing arrangement at each dimer interface may play a role in facilitating target recognition and specificity.

\section{NCS PROTEINS HAVE DISTINCT DIMERIC STRUCTURES}

\section{GCAP1 Forms a Symmetric and Functional Dimer}

Recent NMR (Lim et al., 2009, 2013, 2016) and EPR double electron-electron resonance (DEER; Lim et al., 2018) studies reveal that GCAP1 exists as a dimer in solution. The GCAP1 dimerization is $\mathrm{Ca}^{2+}$-independent and $\mathrm{Ca}^{2+}$-binding to GCAP1 does not appear to cause large changes in the dimer quaternary structure (Lim et al., 2018). A structural model of the GCAP1 dimer was determined recently by DEER (Lim et al., 2018; Figure 2A). The GCAP1 dimer is
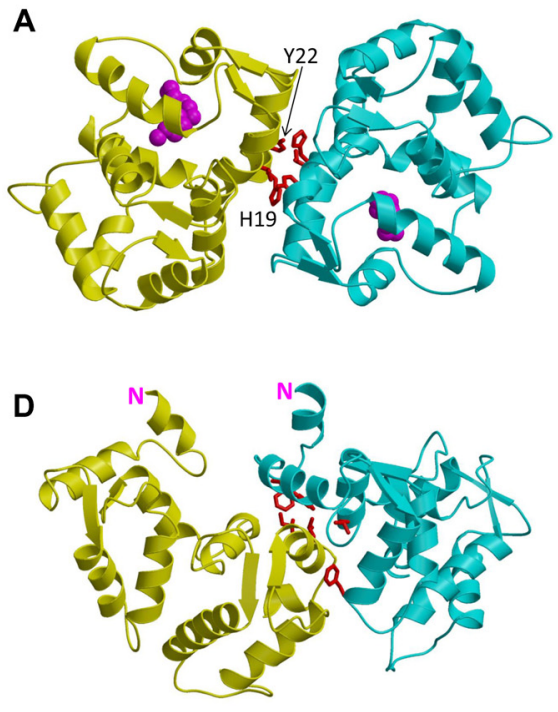
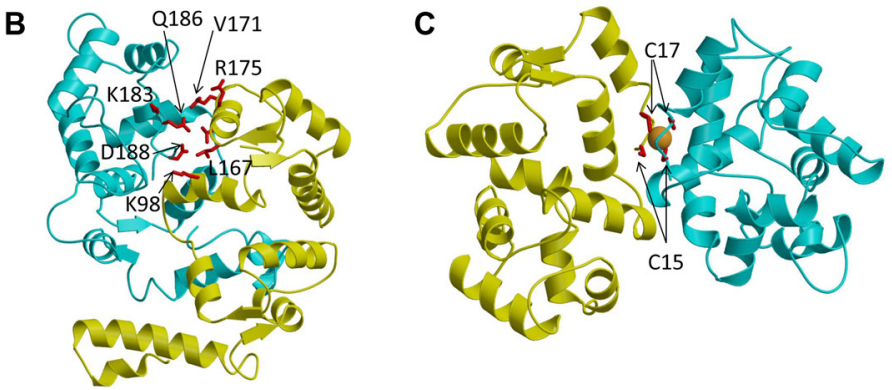

E

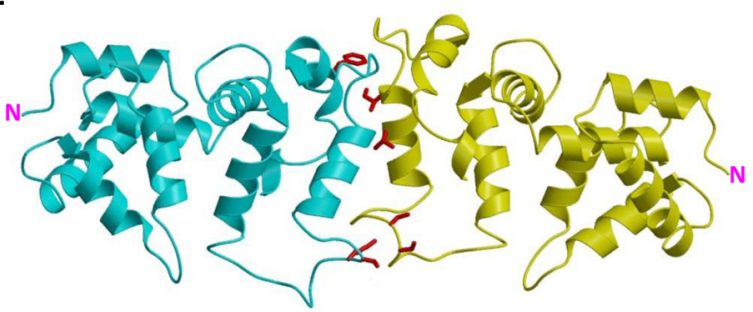

FIGURE 2 | Main chain structures of dimeric NCS proteins: $\mathrm{Ca}^{2+}$-free/Mg${ }^{2+}$-bound GCAP1 (A), Ca ${ }^{2+}$-free GCAP2 (B), Fe ${ }^{2+}-$ bound GCAP5 (C), Ca ${ }^{2+}$-bound recoverin (D) and $\mathrm{Ca}^{2+}$-bound VILIP1 (E). The two separate dimer subunits are colored yellow and cyan. Amino acids at the dimer interface are highlighted red. Fe ${ }^{2+}$ bound to GCAP5 is orange, and N-terminal myristoyl group in GCAP1 is magenta. 

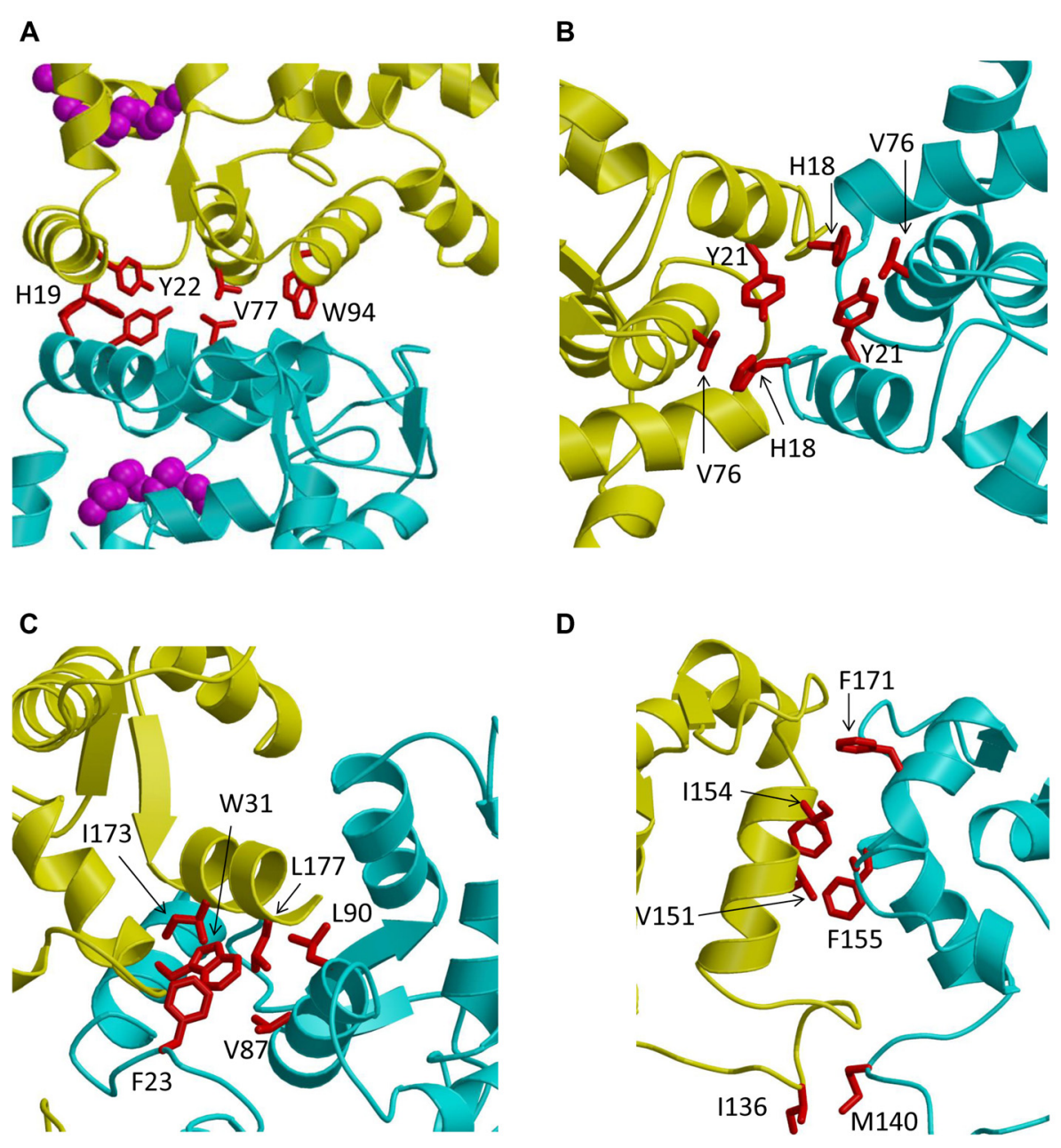

D

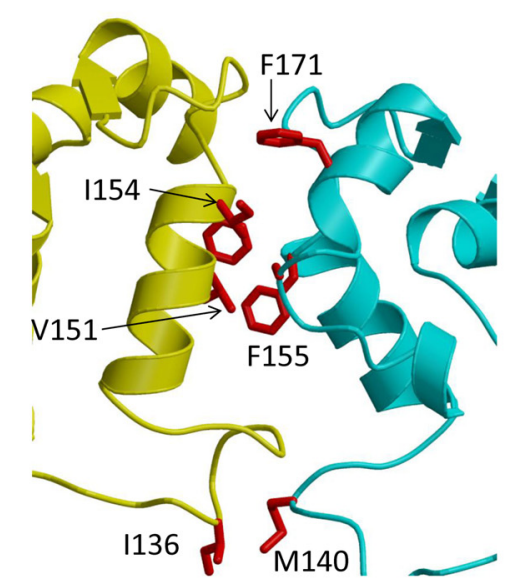

FIGURE 3 | Close-up views of the dimerization interface in GCAP1 (A), GCAP5 (B), recoverin (C) and VILIP1 (D). The two dimer subunits are colored yellow and cyan. Hydrophobic amino acids at the dimer interface are highlighted red.

symmetric (Figure 2A), and is stabilized by hydrophobic contacts at the dimer interface (Figure 3A). The most noteworthy intermolecular contacts involve hydrophobic residues, H19, Y22, V77 and W94 (Figure 3A). In particular, the methyl side-chain atoms of V77 each contact one another at the dimer interface and therefore explain why the V77E mutation dramatically weakens GCAP1 dimerization (Lim et al., 2016). The GCAP1 dimer is further stabilized by aromatic side chains of F73 and W94 that form intermolecular contacts at the dimer interface (Lim et al., 2018). Individual point mutations at the dimer interface in GCAP1 (H19A, Y22A, F73A, V77E and W94A) each weaken the dimerization dissociation constant by more than 10-fold and completely abolish the activation of RetGC by GCAP1 (Lim et al., 2018). Thus, the hydrophobic contacts at the GCAP1 dimer interface (Figure 3A) are essential for both its dimerization and activation of RetGCs. This implies that GCAP1 dimerization may be important for activating RetGC1, which itself is a dimer (Liu et al., 1997; Ramamurthy et al., 2001). Therefore, it is tempting to speculate that the GCAP1 dimer (Figure 2A) may bind to dimeric RetGC1 to form a 2:2 complex. This binding of the GCAP1 dimer is proposed to induce an allosteric conformational change in the RetGC1 dimer in order to modulate the cyclase activity. The allosteric regulation of RetGC activity may involve quaternary structural changes in the $2: 2$ complex akin to quaternary structural changes that regulate $\mathrm{O}_{2}$ binding to hemoglobin (Monod et al., 1965).

\section{GCAP2 Forms an Asymmetric Dimer With a Polar Dimer Interface}

GCAP2 forms a stable dimer in solution (Ames et al., 1999; Ermilov et al., 2001), and the original NMR structure of GCAP2 (Ames et al., 1999) was determined in the presence of detergent that dissociated the dimer into a stably folded monomer. There is some dispute about the $\mathrm{Ca}^{2+}$-dependence of the GCAP2 dimerization. The original work by Ermilov et al. (2001) determined that GCAP2 forms a dimer only in the $\mathrm{Ca}^{2+}$-free state, and the $\mathrm{Ca}^{2+}$-bound GCAP2 was shown to be monomeric. However, a more recent study suggested that GCAP2 can form a dimer in both the $\mathrm{Ca}^{2+}$-free 
and $\mathrm{Ca}^{2+}$-bound states (Pettelkau et al., 2013). A structural model of the GCAP2 dimer (in both $\mathrm{Ca}^{2+}$-free and $\mathrm{Ca}^{2+}$ bound states) was determined recently by mass spectrometry (Pettelkau et al., 2013). $\mathrm{Ca}^{2+}$-binding to GCAP2 does not affect the dimer quaternary structure (Pettelkau et al., 2013), similar to the $\mathrm{Ca}^{2+}$-independent dimer quaternary structure of GCAP1 (Lim et al., 2018). However unlike GCAP1, the GCAP2 dimer is asymmetric (Figure 2B). The residues at the GCAP2 dimer interface (residues K98, L167, V171, R175, K183, Q186, D188 highlighted red in Figure 2B) are not conserved and are completely unrelated to the residues at the GCAP1 interface (highlighted red in Figure 3A). Surprisingly, the GCAP2 interface involves mainly polar and charged residues in contrast to the exclusively hydrophobic interface in GCAP1. The positively charged side-chain atoms of R175 in GCAP2 (yellow colored chain in Figure 2B) are within $5 \AA$ of the polar side-chain atoms of Q186 in the opposite chain (cyan in Figure 2B), and the positively charged side-chain atoms of K98 (yellow chain in Figure 2B) are less than $4 \AA$ from the side chain carboxylate atoms of D188 in the opposite chain (cyan in Figure 2B). These intermolecular contacts at the GCAP2 dimer interface are not conserved in GCAP1 and may explain why the GCAP2 dimer (Figure 2B) is structurally quite different from the GCAP1 dimer (Figure 2A). The dramatically different quaternary structures and dimerization interface for GCAP2 compared to GCAP1 might also explain their functional differences (Duda et al., 2012b; Peshenko et al., 2015).

\section{GCAP5 Dimerization Is Bridged by $\mathrm{Fe}^{2+}$}

Zebrafish photoreceptors contain specific GCAP homologs (GCAP3-5; Imanishi et al., 2004; Rätscho et al., 2009) that are not expressed in mammals. The amino acid sequence of the zebrafish homolog called GCAP5 is the most divergent compared to the amino acid sequences of mammalian GCAP1 and GCAP2 (Figure 1). Two non-conserved Cys residues in GCAP5 (Cys 15 and Cys17) were shown recently to ligate $\mathrm{Fe}^{2+}$ (Lim et al., 2017). $\mathrm{Fe}^{2+}$-binding to GCAP5 serves as a potent inhibitor and the $\mathrm{Fe}^{2+}$-bound GCAP5 is unable to activate RetGC at low $\mathrm{Ca}^{2+}$ levels in light-adapted photoreceptors, suggesting that $\mathrm{Fe}^{2+}$ binding to GCAP5 may serve as a redox sensor for phototransduction in zebrafish photoreceptors (Lim et al., 2017). Structurally, the $\mathrm{Fe}^{2+}$ binding by Cys 15 and Cys17 bridges two GCAP5 molecules into a $\left[\mathrm{Fe}(\mathrm{SCys})_{4}\right]$ dimeric complex (Lim et al., 2017) like that observed previously in two-iron superoxide reductases (deMaré et al., 1996; Min et al., 2001; Emerson et al., 2003). The GCAP5 dimer has a symmetric structure (Figure 2C) somewhat similar to that of GCAP1 (Figure 2A). The GCAP5 dimer interface contains hydrophobic residues (H18, Y21 and V76 in Figure 3B) that are conserved in the GCAP1 dimer (Figure 3A). However unlike GCAP1, the GCAP5 dimer contains a single $\mathrm{Fe}^{2+}$ bound at the dimer interface that is ligated by Cys15 and Cys17 in both dimer subunits (colored yellow and cyan in Figure 2C) of the symmetric GCAP5 dimer. The four cysteinyl thiolate groups that ligate the bound $\mathrm{Fe}^{2+}$ (Figure 2C) are similar in structure to the four Cys residues found in the
Cys4 zinc finger motif that binds to $\mathrm{Zn}^{2+}$ (Tang et al., 2014). The structural similarity to the Cys4 zinc finger suggests that GCAP5 may also bind to $\mathrm{Zn}^{2+}$ in place of $\mathrm{Fe}^{2+}$. $\mathrm{Zn}^{2+}$ is transported into retinal photoreceptor cells and has been suggested to play a role in phototransduction (Redenti et al., 2007). It is tempting to speculate that GCAP5 might serve as a $\mathrm{Zn}^{2+}$ sensor in the zebrafish photoreceptor. Future studies are needed to probe whether $\mathrm{Zn}^{2+}$ can bind to GCAP5 and test whether $\mathrm{Zn}^{2+}$ binding to GCAP5 (like Fe ${ }^{2+}$ binding) can also regulate zebrafish RetGCs during visual phototransduction.

\section{$\mathrm{Ca}^{2+}$-Induced Dimerization of $\mathrm{Ca}^{2+}$-Myristoyl Switch Proteins}

The $\mathrm{Ca}^{2+}$-myristoyl switch proteins, recoverin (Myers et al., 2013) and VILIP1 (Li et al., 2011) both exhibit $\mathrm{Ca}^{2+}$-induced dimerization that enhances their membrane anchoring. The dimeric structure of $\mathrm{Ca}^{2+}$-bound recoverin (Figure 2D) places both of its exposed N-terminal myristoyl groups (highlighted magenta in Figure 2D) pointing in the same direction to serve as a dual pronged myristate membrane anchor (Figure 4). The recoverin dimer is stabilized mostly by hydrophobic intermolecular contacts (Figure 3C). In essence, the dimer

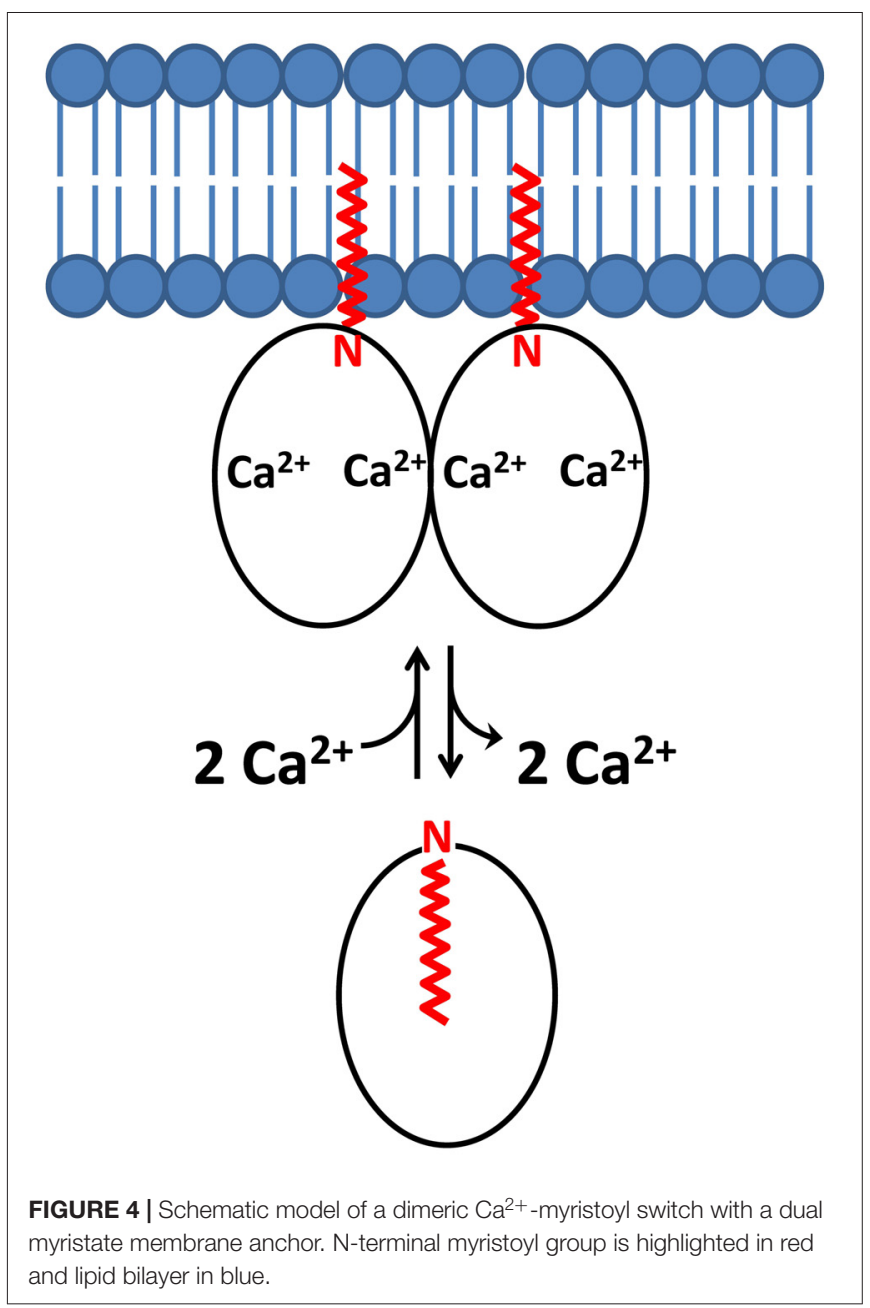


interface is formed by the exposed hydrophobic residues in the exiting helix of EF4 (residues I173 and L177) that fit snuggly into the exposed hydrophobic groove between EF1 and EF2. Aliphatic side chain atoms of I173 and L177 from EF4 (yellow chain in Figure 3C) make intermolecular contacts with aromatic side chain atoms of F23 and W31 (cyan chain in Figure 3C). Additional intermolecular contacts are formed by side chain atoms of L90 and L177. The N-terminal domain residues (F23, W31, V87 and L90) at the dimer interface are the same residues that interact with the sequestered myristoyl group in $\mathrm{Ca}^{2+}$-free recoverin (Tanaka et al., 1995; Ames et al., 1997; Ames and Lim, 2012). The $\mathrm{Ca}^{2+}$-induced extrusion of the myristoyl group causes the exposure of these residues (F23, W31, V87 and L90), making them accessible to promote dimerization of the $\mathrm{Ca}^{2+}$-bound protein. The $\mathrm{Ca}^{2+}$-induced dimerization of recoverin enhances membrane binding by creating a dual pronged myristoyl anchor (Figure 4). The membrane anchored recoverin dimer bound to two rhodopsin kinase molecules in the dark may serve to place the two kinase molecules in close proximity of dimeric rhodopsin and therefore facilitate their rapid binding upon light activation (Ames et al., 2006; Myers et al., 2013).

The dimeric structure of VILIP-1 contains two protein subunits attached at their exposed C-terminal ends, forming an elongated structure (see yellow and cyan chains in Figure 2D). The exposed helices of EF4 are packed against each other at the dimer interface, forming an intermolecular four helix bundle. The VILIP1 dimer interface is almost entirely hydrophobic (Figure 3D). Exposed residues on the entering helix of EF4 (V151 and I154) in the yellow chain of Figure 2D make intermolecular contacts with exposed hydrophobic residues (F155 and F171) in the cyan colored chain. Additional intermolecular hydrophobic contacts are formed by I136 and M140 located in the region between EF3 and EF4. The intermolecular hydrophobic contacts are essential for VILIP1 dimerization as demonstrated by mutants (I136G, V151G and F155G) that each weaken the dimerization affinity (Li et al., 2011). The VILIP1 dimer structure has its N-terminal myristoyl group from each dimer subunit pointing upward in the same direction to serve as a dual-pronged anchor for targeting VILIP-1 to membranes (Figure 4). The opposite end of the VILIP1 dimer contains an exposed hydrophobic crevice in the N-terminal domain (residues F22, W30, L43, F48, I51, Y52, F55, F56, F72, F82, F85, I86, A88, L89) that are suggested to interact with hydrophobic segments of target proteins (Li et al., 2011).

\section{FUNCTIONAL IMPLICATIONS OF NCS DIMERIZATION}

\section{Recoverin and VILIP1 Dimers Enhance Membrane Targeting Affinity}

The $\mathrm{Ca}^{2+}$-bound dimeric structures of recoverin (Figure 2C) and VILIP1 (Figure 2D) have their N-terminal myristoyl groups pointing in the same direction toward the membrane surface (Figure 4). The juxta positioning of the two myristoyl groups creates a dual pronged membrane anchor that entropically enhances membrane binding. Since the effect of dimerization is multiplicative, a dimeric myristoyl switch protein is predicted to bind to lipid bilayer membranes with $10^{4}$-fold higher affinity $\left(K_{\mathrm{d}}=10^{-8} \mathrm{M}\right)$ compared to the affinity of a monomeric $\mathrm{Ca}^{2+}$. myristoyl switch $\left(K_{\mathrm{d}}=10^{-4} \mathrm{M}\right.$; Peitzsch and McLaughlin, 1993; Kim et al., 1994; Dell'Orco et al., 2012). In other words, the membrane binding dissociation constant of the dimer $\left(K_{\mathrm{d}}(\right.$ dimer $\left.)\right)$ is equal to the square of the dissociation constant of the monomer: $K_{\mathrm{d}}$ (dimer) $=K_{\mathrm{d}}$ (monomer $)^{2}=\left(10^{-4}\right.$ $M)^{2}=10^{-8} \mathrm{M}$. Thus, the membrane binding affinity of $\mathrm{Ca}^{2+}$. myristoyl switch proteins is predicted here to be dramatically enhanced by the combined effect of both $\mathrm{Ca}^{2+}$-binding and protein dimerization. Dimerization of $\mathrm{Ca}^{2+}$-myristoyl switch proteins may also entropically enhance its binding to dimeric protein targets, as was suggested for the binding of dimeric $\mathrm{Ca}^{2+}$-bound recoverin to dimeric rhodopsin (Myers et al., 2013).

\section{GCAP1 Dimerization in Retinal Photoreceptors}

An important unresolved question in visual phototransduction is how the $\mathrm{Ca}^{2+}$-free GCAP proteins are able to specifically bind and activate RetGC in light-adapted photoreceptors, and conversely how $\mathrm{Ca}^{2+}$-bound GCAPs inhibit RetGC in dark-adapted photoreceptors. The crystal structure of the $\mathrm{Ca}^{2+}$-bound GCAP1 inhibitory state (Stephen et al., 2007) is overall similar to the recent NMR structure of the $\mathrm{Ca}^{2+}$. free GCAP1 activator state (Lim et al., 2016). Although, the $\mathrm{Ca}^{2+}$-induced changes in tertiary structure for GCAP1 appear moderately small, these small tertiary structural changes may promote a functional change in the quaternary structure of the GCAP1 dimer that in turn could modulate the quaternary structure of the RetGC1 dimer in order to allosterically regulate cyclase activity. In other words, small changes in tertiary structure may result in much larger changes in quaternary structure in order to amplify the response. Consistent with this prediction, mutations in GCAP1 (H19E, Y22E, F73E, V77E and W94E) that each weaken dimerization also abolish activation of the cyclase (Lim et al., 2018). These mutants indicate that GCAP1 dimerization is necessary and sufficient to activate RetGC, and furthermore suggests that a pre-formed GCAP1 dimer may facilitate its binding to the dimeric RetGC and thus stabilize a high affinity 2:2 target complex.

An alternative view is that the GCAP1 dimer that has been detected in solution and in the absence of RetGC may not necessarily exist in the presence of RetGC, because residues in the GCAP1 dimer interface (Figure 3A) appear to overlap with residues that interact with RetGC (Peshenko et al., 2014). In this scenario, the residues at the GCAP1 dimerization site may prefer to interact with RetGC (rather than itself) in the presence of saturating RetGC, and the binding of RetGC to GCAP1 in this case would be expected to prevent GCAP1 dimerization. To distinguish whether GCAP1 dimerization facilitates or opposes RetGC binding, future studies are needed to probe whether or not the structure of the GCAP1 dimer 
(Figure 2A) will remain intact when GCAP1 is bound to RetGC.

\section{CONCLUSION}

The dimerization of NCS proteins could help explain how these highly conserved proteins adopt distinctive structures that recognize many different targets. Recent structures of dimeric forms of GCAP1, GCAP2, GCAP5, recoverin and VILIP1 each reveal a unique quaternary structure at the dimer interface. GCAP1 forms a symmetric dimer that consolidates key residues for interacting with RetGCs, whereas GCAP2 forms an asymmetric dimer. The dimerization of GCAPs may facilitate allosteric regulation of its dimeric target protein (RetGC), which

\section{REFERENCES}

Ames, J. B., Dizhoor, A. M., Ikura, M., Palczewski, K., and Stryer, L. (1999). Threedimensional structure of guanylyl cyclase activating protein-2, a calciumsensitive modulator of photoreceptor guanylyl cyclases. J. Biol. Chem. 274, 19329-19337. doi: 10.1074/jbc.274.27.19329

Ames, J. B., and Ikura, M. (2002). Structure and membrane-targeting mechanism of retinal $\mathrm{Ca}^{2+}$-binding proteins, recoverin and GCAP-2. Adv. Exp. Med. Biol. 514, 333-348. doi: 10.1007/978-1-4615-0121-3_20

Ames, J. B., Ishima, R., Tanaka, T., Gordon, J. I., Stryer, L., and Ikura, M. (1997). Molecular mechanics of calcium-myristoyl switches. Nature 389, 198-202. doi: $10.1038 / 38310$

Ames, J. B., Levay, K., Wingard, J. N., Lusin, J. D., and Slepak, V. Z. (2006). Structural basis for calcium-induced inhibition of rhodopsin kinase by recoverin. J. Biol. Chem. 281, 37237-37245. doi: 10.1074/jbc.m606913200

Ames, J. B., and Lim, S. (2012). Molecular structure and target recognition of neuronal calcium sensor proteins. Biochim. Biophys. Acta 1820, 1205-1213. doi: 10.1016/j.bbagen.2011.10.003

Ames, J. B., Porumb, T., Tanaka, T., Ikura, M., and Stryer, L. (1995). Aminoterminal myristoylation induces cooperative calcium binding to recoverin. J. Biol. Chem. 270, 4526-4533. doi: 10.1074/jbc.270.9.4526

Ames, J. B., Tanaka, T., Stryer, L., and Ikura, M. (1996). Portrait of a myristoyl switch protein. Curr. Opin. Struct. Biol. 6, 432-438. doi: 10.1016/s0959440x(96)80106-0

Augustine, G. J., Santamaria, F., and Tanaka, K. (2003). Local calcium signaling in neurons. Neuron 40, 331-346. doi: 10.1016/s0896-6273(03)00639-1

Baehr, W., and Palczewski, K. (2007). Guanylate cyclase-activating proteins and retina disease. Subcell. Biochem. 45, 71-91. doi: 10.1007/978-1-4020-6191-2_4

Bernstein, H.-G., Baumann, B., Danos, P., Diekmann, S., Bogerts, B., Gundelfinger, E. D., et al. (1999). Regional and cellular distribution of neural visinin-like protein immunoreactivities (VILIP-1 and VILIP-3) in human brain. J. Neurocytol. 28, 655-662. doi: 10.1023/A:1007056731551

Berridge, M. J., Lipp, P., and Bootman, M. D. (2000). The versatility and universality of calcium signalling. Nat. Rev. Mol. Cell Biol. 1, 11-21. doi: 10.1038/35036035

Bondarenko, V. A., Hayashi, F., Usukura, J., and Yamazaki, A. (2010). Involvement of rhodopsin and ATP in the activation of membranous guanylate cyclase in retinal photoreceptor outer segments (ROS-GC) by GC-activating proteins (GCAPs): a new model for ROS-GC activation and its link to retinal diseases. Mol. Cell. Biochem. 334, 125-139. doi: 10.1007/s11010-009-0323-y

Brackmann, M., Zhao, C., Kuhl, D., Manahan-Vaughan, D., and Braunewell, K.-H. (2004). MGluRs regulate the expression of neuronal calcium sensor proteins NCS-1 and VILIP-1 and the immediate early gene arg3.1/arc in the hippocampus in vivo. Biochem. Biophys. Res. Commun. 322, 1073-1079. doi: 10.1016/j.bbrc.2004.08.028

Braunewell, K.-H. (2005). The darker side of $\mathrm{Ca}^{2+}$ signaling by neuronal $\mathrm{Ca}^{2+}$ sensor proteins: from Alzheimer's disease to cancer. Trends Pharmacol. Sci. 26, 345-351. doi: 10.1016/j.tips.2005.04.008

Braunewell, K.-H., Brackmann, M., and Manahan-Vaughan, D. (2003). Group I mGlu receptors regulate the expression of the neuronal calcium sensor may help explain the steep $\mathrm{Ca}^{2+}$-dependent regulation of RetGC. Dimerization of both recoverin and VILIP1 creates a dual pronged myristate membrane anchor that enhances membrane targeting and may facilitate recognition of dimeric membranebound targets.

\section{AUTHOR CONTRIBUTIONS}

JA wrote and conceived the entire manuscript.

\section{FUNDING}

This work was supported by grants to JA (EY012347) from the National Institutes of Health (NIH), and Eye Institute.

protein VILIP-1 in vitro and in vivo: implications for mGlu receptor-dependent hippocampal plasticity? Neuropharmacology 44, 707-715. doi: 10.1016/s00283908(03)00051-0

Braunewell, K.-H., and Gundelfinger, E. D. (1999). Intracellular neuronal calcium sensor proteins: a family of EF-hand calcium-binding proteins in search of a function. Cell Tissue Res. 295, 1-12. doi: 10.1007/s004410051207

Braunewell, K.-H., and Klein-Szanto, A. J. (2009). Visinin-like proteins (VSNLs): interaction partners and emerging functions in signal transduction of a subfamily of neuronal $\mathrm{Ca}^{2+}$-sensor proteins. Cell Tissue Res. 335, 301-316. doi: 10.1007/s00441-008-0716-3

Burgoyne, R. D., O'Callaghan, D. W., Hasdemir, B., Haynes, L. P., and Tepikin, A. V. (2004). Neuronal $\mathrm{Ca}^{2+}$-sensor proteins: multitalented regulators of neuronal function. Trends Neurosci. 27, 203-209. doi: 10.1016/j.tins.2004. 01.010

Burgoyne, R. D., and Weiss, J. L. (2001). The neuronal calcium sensor family of $\mathrm{Ca}^{2+}$-binding proteins. Biochem. J. 354:727. doi: 10.1042/0264-6021:3540727y

Calvert, P. D., Klenchin, V. A., and Bownds, M. D. (1995). Rhodopsin kinase inhibition by recoverin. Function of recoverin myristoylation. J. Biol. Chem. 270, 24127-24129. doi: 10.1074/jbc.270.41.24127

Chen, C.-K., Inglese, J., Lefkowitz, R. J., and Hurley, J. B. (1995). Ca ${ }^{2+}$ dependent interaction of recoverin with rhodopsin kinase. J. Biol. Chem. 270, 18060-18066. doi: 10.1074/jbc.270.30.18060

Chen, C.-K., Woodruff, M. L., Chen, F. S., Chen, Y., Cilluffo, M. C., Tranchina, D., et al. (2012). Modulation of mouse rod response decay by rhodopsin kinase and recoverin. J. Neurosci. 32, 15998-16006. doi: 10.1523/jneurosci.1639-12.2012

Cox, J. A., Durussel, I., Comte, M., Nef, S., Nef, P., Lenz, S. E., et al. (1994). Cation binding and conformational changes in VILIP and NCS-1, two neuron-specific calcium-binding proteins. J. Biol. Chem. 269, 32807-32813.

Dell'Orco, D., Sulmann, S., Linse, S., and Koch, K. W. (2012). Dynamics of conformational $\mathrm{Ca}^{2+}$-switches in signaling networks detected by a planar plasmonic device. Anal. Chem. 84, 2982-2989. doi: 10.1021/ac300213j

deMaré, F., Kurtz, D., and Nordlund, P. (1996). The structure of Desulfovibrio vulgaris rubrerythrin reveals a unique combination of rubredoxin-like FeS4 and ferritin-like diiron domains. Nat. Struct. Biol. 3, 539-546. doi: 10.1038/nsb0696-539

Dizhoor, A. M., Boikov, S. G., and Olshevskaya, E. V. (1998). Constitutive activation of photoreceptor guanylate cyclase by Y99C mutant of GCAP-1. Possible role in causing human autosomal dominant cone degeneration. J. Biol. Chem. 273, 17311-17314. doi: 10.1074/jbc.273.28.17311

Dizhoor, A. M., Chen, C. K., Olshevskaya, E., Sinelnikova, V. V., Phillipov, P., and Hurley, J. B. (1993). Role of the acylated amino terminus of recoverin in $\mathrm{Ca}^{2+}$. dependent membrane interaction. Science 259, 829-832. doi: 10.1126/science. 8430337

Dizhoor, A. M., Ericsson, L. H., Johnson, R. S., Kumar, S., Olshevskaya, E., Zozulya, S., et al. (1992). The NH2 terminus of retinal recoverin is acylated by a small family of fatty acids. J. Biol. Chem. 267, 16033-16036.

Dizhoor, A. M., and Hurley, J. B. (1996). Inactivation of EF-hands makes GCAP-2 (p24) a constitutive activator of photoreceptor guanylyl cyclase by preventing a $\mathrm{Ca}^{2+}$-induced "activator-to-inhibitor" transition. J. Biol. Chem. 271, 19346-19350. doi: 10.1074/jbc.271.32.19346 
Dizhoor, A. M., Lowe, D. G., Olsevskaya, E. V., Laura, R. P., and Hurley, J. B. (1994). The human photoreceptor membrane guanylyl cyclase, RetGC, is present in outer segments and is regulated by calcium and a soluble activator. Neuron 12, 1345-1352. doi: 10.1016/0896-6273(94)90449-9

Dizhoor, A. M., Ray, S., Kumar, S., Niemi, G., Spencer, M., Brolley, D., et al. (1991). Recoverin: a calcium sensitive activator of retinal rod guanylate cyclase. Science 251, 915-918. doi: 10.1126/science.1672047

Duda, T., Jankowska, A., Venkataraman, V., Nagele, R. G., and Sharma, R. K. (2001). A novel calcium-regulated membrane guanylate cyclase transduction system in the olfactory neuroepithelium. Biochemistry 40, 12067-12077. doi: 10.1021/bi0108406

Duda, T., Pertzev, A., Koch, K. W., and Sharma, R. K. (2012a). Antithetical modes of and the $\mathrm{Ca}^{2+}$ sensors targeting in ANF-RGC and ROS-GC1 membrane guanylate cyclases. Front. Mol. Neurosci. 5:44. doi: 10.3389/fnmol.2012. 00044

Duda, T., Pertzev, A., and Sharma, R. K. (2012b). Differential $\mathrm{Ca}^{2+}$ sensor guanylate cyclase activating protein modes of photoreceptor rod outer segment membrane guanylate cyclase signaling. Biochemistry 51, 4650-4657. doi: 10.1021/bi300572w

Emerson, J. P., Cabelli, D. E., and Kurtz, D. M.Jr. (2003). An engineered two-iron superoxide reductase lacking the $\left[\mathrm{Fe}(\mathrm{SCys})_{4}\right]$ site retains its catalytic properties in vitro and in vivo. Proc. Natl. Acad. Sci. U S A 100, 3802-3807. doi: 10.1073/pnas.0537177100

Erickson, M. A., Lagnado, L., Zozulya, S., Neubert, T. A., Stryer, L., and Baylor, D. A. (1998). The effect of recombinant recoverin on the photoresponse of truncated rod photoreceptors. Proc. Natl. Acad. Sci. U S A 95, 6474-6479. doi: 10.1073/pnas.95.11.6474

Ermilov, A. N., Olshevskaya, E. V., and Dizhoor, A. M. (2001). Instead of binding calcium, one of the EF-hand structures in guanylyl cyclase activating protein-2 is required for targeting photoreceptor guanylyl cyclase. J. Biol. Chem. 276, 48143-48148. doi: 10.1074/jbc.m107539200

Frins, S., Bönigk, W., Müller, F., Kellner, R., and Koch, K. W. (1996). Functional characterization of a guanylyl cyclase activating protein from vertebrate rods. Cloning, heterologous expression and localization. J. Biol. Chem. 271, 8022-8027. doi: 10.1074/jbc.271.14.8022

Gierke, P., Zhao, C., Bernstein, H. G., Noack, C., Anand, R., Heinemann, U., et al. (2008). Implication of neuronal $\mathrm{Ca}^{2+}$-sensor protein VILIP-1 in the glutamate hypothesis of schizophrenia. Neurobiol. Dis. 32, 162-175. doi: 10.1016/j.nbd. 2008.07.008

Haynes, L. P., McCue, H. V., and Burgoyne, R. D. (2012). Evolution and functional diversity of the Calcium Binding Proteins (CaBPs). Front. Mol. Neurosci. 5:9. doi: 10.3389/fnmol.2012.00009

Hidaka, H., and Okazaki, K. (1993). Neurocalcin family: a novel calcium-binding protein abundant in bovine central nervous system. Neurosci. Res. 16, 73-77. doi: 10.1016/0168-0102(93)90074-z

Hughes, R. E., Brzovic, P. S., Dizhoor, A. M., Klevit, R. E., and Hurley, J. B. (1998). $\mathrm{Ca}^{2+}$-dependent conformational changes in bovine GCAP-2. Protein Sci. 7, 2675-2680. doi: 10.1002/pro.5560071222

Hwang, J.-Y., and Koch, K.-W. (2002). Calcium- and myristoyl-dependent properties of guanylate cyclase-activating protein-1 and protein-2. Biochemistry 41, 13021-13028. doi: 10.1021/bi026618y

Ikura, M. (1996). Calcium binding and conformational response in EF-hand proteins. Trends Biochem. Sci. 21, 14-17. doi: 10.1016/s0968-0004(06) 80021-6

Imanishi, Y., Yang, L., Sokal, I., Filipek, S., Palczewski, K., and Baehr, W. (2004). Diversity of guanylate cyclase-activating proteins (GCAPs) in teleost fish: characterization of three novel GCAPs (GCAP4, GCAP5, GCAP7) from zebrafish (Danio rerio) and prediction of eight GCAPs (GCAP1-8) in pufferfish (Fugu rubripes). J. Mol. Evol. 59, 204-217. doi: 10.1007/s00239-004-2614-y

Jiang, L., and Baehr, W. (2010). GCAP1 mutations associated with autosomal dominant cone dystrophy. Adv. Exp. Med. Biol. 664, 273-282. doi: 10.1007/9781-4419-1399-9_31

Kawamura, S. (1993). Rhodopsin phosphorylation as a mechanism of cyclic GMP phosphodiesterase regulation by S-modulin. Nature 362, 855-857. doi: $10.1038 / 362855 \mathrm{a} 0$

Kawamura, S., and Murakami, M. (1991). Calcium-dependent regulation of cyclic GMP phosphodiesterase by a protein from frog retinal rods. Nature 349, 420-423. doi: 10.1038/349420a0
Kim, J., Shishido, T., Jiang, X., Aderem, A., and McLaughlin, S. (1994). Phosphorylation, high ionic strength and calmodulin reverse the binding of MARCKS to phospholipid vesicles. J. Biol. Chem. 269, 28214-28219.

Klenchin, V. A., Calvert, P. D., and Bownds, M. D. (1995). Inhibition of rhodopsin kinase by recoverin. Further evidence for a negative feedback system in phototransduction. J. Biol. Chem. 270, 16147-16152. doi: 10.1074/jbc.270.27. 16147

Kobayashi, M., Takamatsu, K., Saitoh, S., Miura, M., and Noguchi, T. (1992). Molecular cloning of hippocalcin, a novel calcium-binding protein of the recoverin family exclusively expressed in hippocampus. Biochem. Biophys. Res. Commun. 189, 511-517. doi: 10.1016/0006-291x(92)91587-g

Kobayashi, M., Takamatsu, K., Saitoh, S., and Noguchi, T. (1993). Myristoylation of hippocalcin is linked to its calcium-dependent membrane association properties. J. Biol. Chem. 268, 18898-18904.

Komolov, K. E., Senin, I. I., Kovaleva, N. A., Christoph, M. P., Churumova, V. A., Grigoriev, I. I., et al. (2009). Mechanism of rhodopsin kinase regulation by recoverin. J. Neurochem. 110, 72-79. doi: 10.1111/j.1471-4159.2009.06118.x

Ladant, D. (1995). Calcium and membrane binding properties of bovine neurocalcin expressed in Escherichia coli. J. Biol. Chem. 270, 3179-3185.

Li, C., Chan, J., Haeseleer, F., Mikoshiba, K., Palczewski, K., Ikura, M., et al. (2009). Structural insights into $\mathrm{Ca}^{2+}$-dependent regulation of inositol 1,4,5-trisphosphate receptors by CaBP1. J. Biol. Chem. 284, 2472-2481. doi: 10.1074/jbc.M806513200

Li, C., Lim, S., Braunewell, K. H., and Ames, J. B. (2016). Structure and calcium binding properties of a neuronal calcium-myristoyl switch protein, visinin-like protein 3. PLoS One 11:e0165921. doi: 10.1371/journal.pone.01 65921

Li, C., Pan, W., Braunewell, K. H., and Ames, J. B. (2011). Structural analysis of $\mathrm{Mg}^{2+}$ and $\mathrm{Ca}^{2+}$ binding, myristoylation, and dimerization of the neuronal calcium sensor and visinin-like protein 1 (VILIP-1). J. Biol. Chem. 286, 6354-6366. doi: 10.1074/jbc.M110.173724

Lim, S., Peshenko, I. V., Dizhoor, A. M., and Ames, J. B. (2009). Effects of $\mathrm{Ca}^{2+}$, $\mathrm{Mg}^{2+}$, and myristoylation on guanylyl cyclase activating protein 1 structure and stability. Biochemistry 48, 850-862. doi: 10.1021/bi801897p

Lim, S., Peshenko, I. V., Dizhoor, A. M., and Ames, J. B. (2013). Structural insights for activation of retinal guanylate cyclase by GCAP1. PLoS One 8:e81822. doi: 10.1371/journal.pone.0081822

Lim, S., Peshenko, I. V., Olshevskaya, E. V., Dizhoor, A. M., and Ames, J. B. (2016). Structure of guanylyl cyclase activator protein 1 (GCAP1) mutant V77E in a $\mathrm{Ca}^{2+}$-free $/ \mathrm{Mg}^{2+}$-bound activator state. J. Biol. Chem. 291, 4429-4441. doi: 10.1074/jbc.M115.696161

Lim, S., Roseman, G., Peshenko, I., Manchala, G., Cudia, D., Dizhoor, A. M., et al. (2018). Retinal guanylyl cyclase activating protein 1 forms a functional dimer. PLoS One 13:e0193947. doi: 10.1371/journal.pone.0193947

Lim, S., Scholten, A., Manchala, G., Cudia, D., Zlomke-Sell, S. K., Koch, K. W., et al. (2017). Structural characterization of ferrous ion binding to retinal guanylate cyclase activator protein 5 from zebrafish photoreceptors. Biochemistry 56, 6652-6661. doi: 10.1021/acs.biochem.7b01029

Lim, S., Strahl, T., Thorner, J., and Ames, J. B. (2011). Structure of a $\mathrm{Ca}^{2+}$. myristoyl switch protein that controls activation of a phosphatidylinositol 4-kinase in fission yeast. J. Biol. Chem. 286, 12565-12577. doi: 10.1074/jbc. M110.208868

Lin, L., Jeancios, E. M., Treuil, M., Braunewell, K. H., Gundelfinger, E. D., and Anand, R. (2002). The calcium sensor protein visinin-like protein1 modulates the surface expression and agonist sensitivity of the $\alpha 4 \beta 2$ nicotinic acetylcholine receptor. J. Biol. Chem. 277, 41872-41878. doi: 10.1074/jbc. M206857200

Liu, Y., Ruoho, A. E., Rao, V. D., and Hurley, J. H. (1997). Catalytic mechanism of the adenylyl and guanylyl cyclases: modeling and mutational analysis. Proc. Natl. Acad. Sci. U S A 94, 13414-13419. doi: 10.1073/pnas.94.25.13414

Makino, C. L., Dodd, R. L., Chen, J., Burns, M. E., Roca, A., Simon, M. I., et al. (2004). Recoverin regulates light-dependent phosphodiesterase activity in retinal rods. J. Gen. Physiol. 123, 729-741. doi: 10.1085/jgp.2003 08994

McFerran, B. W., Graham, M. E., and Burgoyne, R. D. (1998). Neuronal Ca ${ }^{2+}$ sensor 1 , the mammalian homologue of frequenin, is expressed in chromaffin and PC12 cells and regulates neurosecretion from dense-core granules. J. Biol. Chem. 273, 22768-22772. doi: 10.1074/jbc.273.35.22768 
Min, T., Ergenekan, C. E., Eidsness, M. K., Ichiye, T., and Kang, C. (2001). Leucine 41 is a gate for water entry in the reduction of Clostridium pasteurianum rubredoxin. Protein Sci. 10, 613-621. doi: 10.1110/gad.34501

Moncrief, N. D., Kretsinger, R. H., and Goodman, M. (1990). Evolution of EF-hand calcium-modulated proteins. J. Mol. Evol. 30, 522-562. doi: $10.1007 / \mathrm{bf} 02101108$

Monod, J., Wyman, J., and Changeux, J. P. (1965). On the nature of allosteric transitions: a plausible model. J. Mol. Biol. 12, 88-118. doi: 10.1016/s00222836(65)80285-6

Myers, W. K., Xu, X., Li, C., Lagerstedt, J. O., Budamagunta, M. S., Voss, J. C., et al. (2013). Double electron-electron resonance probes $\mathrm{Ca}^{2+}$-induced conformational changes and dimerization of recoverin. Biochemistry 52, 5800-5808. doi: 10.1021/bi400538w

Olshevskaya, E. V., Hughes, R. E., Hurley, J. B., and Dizhoor, A. M. (1997). Calcium binding, but not a calcium-myristoyl switch, controls the ability of guanylyl cyclase-activating protein GCAP-2 to regulate photoreceptor guanylyl cyclase. J. Biol. Chem. 272, 14327-14333. doi: 10.1074/jbc.272.22.14327

Palczewski, K., Polans, A. S., Baehr, W., and Ames, J. B. (2000). $\mathrm{Ca}^{2+}$. binding proteins in the retina: structure, function and the etiology of human visual diseases. Bioessays 22, 337-350. doi: 10.1002/(SICI)15211878(200004)22:4<337::AID-BIES4>3.0.CO;2-Z

Palczewski, K., Sokal, I., and Baehr, W. (2004). Guanylate cyclase-activating proteins: structure, function and diversity. Biochem. Biophys. Res. Commun. 322, 1123-1130. doi: 10.1016/j.bbrc.2004.07.122

Palczewski, K., Subbaraya, I., Gorczyca, W. A., Helekar, B. S., Ruiz, C. C., Ohguro, H., et al. (1994). Molecular cloning and characterization of retinal photoreceptor guanylyl cyclase-activating protein. Neuron 13, 395-404. doi: 10.1016/0896-6273(94)90355-7

Paterlini, M., Revilla, V., Grant, A. L., and Wisden, W. (2000). Expression of the neuronal calcium sensor protein family in the rat brain. Neuroscience 99 , 205-216. doi: 10.1016/s0306-4522(00)00201-3

Peitzsch, R. M., and McLaughlin, S. (1993). Binding of acylated peptides and fatty acids to phospholipid vesicles: pertinence to myristoylated proteins. Biochemistry 32, 10436-10443. doi: 10.1021/bi00090a020

Permyakov, S. E., Nazipova, A. A., Denesyuk, A. I., Bakunts, A. G., Zinchenko, D. V., Lipkin, V. M., et al. (2007). Recoverin as a redox-sensitive protein. J. Proteome Res. 6, 1855-1863. doi: 10.1021/pr070015x

Permyakov, S. E., Zernii, E. Y., Knyazeva, E. L., Denesyuk, A. I., Nazipova, A. A., Kolpakova, T. V., et al. (2012). Oxidation mimicking substitution of conservative cysteine in recoverin suppresses its membrane association. Amino Acids 42, 1435-1442. doi: 10.1007/s00726-011-0843-0

Peshenko, I. V., and Dizhoor, A. M. (2006). $\mathrm{Ca}^{2+}$ and $\mathrm{Mg}^{2+}$ binding properties of GCAP-1. Evidence that $\mathrm{Mg}^{2+}$-bound form is the physiological activator of photoreceptor guanylyl cyclase. J. Biol. Chem. 281, 23830-23841. doi: 10.1074/jbc.m600257200

Peshenko, I. V., and Dizhoor, A. M. (2007). Activation and inhibition of photoreceptor guanylyl cyclase by guanylyl cyclase activating protein 1 (GCAP1): the functional role of $\mathrm{Mg}^{2+} / \mathrm{Ca}^{2+}$ exchange in EF-hand domains. J. Biol. Chem. 282, 21645-21652. doi: 10.1074/jbc.m702368200

Peshenko, I. V., Olshevskaya, E. V., and Dizhoor, A. M. (2015). Evaluating the role of retinal guanylyl cyclase 1 (RetGC1) domains in binding guanylyl cyclase activating proteins (GCAP). J. Biol. Chem. 290, 6913-6924. doi: 10.1074/jbc. M114.629642

Peshenko, I. V., Olshevskaya, E. V., Lim, S., Ames, J. B., and Dizhoor, A. M. (2014). Identification of target binding site in photoreceptor guanylyl cyclase-activating protein 1 (GCAP1). J. Biol. Chem. 289, 10140-10154. doi: 10.1074/jbc.M113.540716

Pettelkau, J., Schröder, T., Ihling, C. H., Olausson, B. E., Kölbel, K., Lange, C., et al. (2012). Structural Insights into retinal guanylylcyclase-GCAP-2 interaction determined by cross-linking and mass spectrometry. Biochemistry 51, 4932-4949. doi: 10.1021/bi300064v

Pettelkau, J., Thondorf, I., Theisgen, S., Lilie, H., Schröder, T., Arlt, C., et al. (2013). Structural analysis of guanylyl cyclase-activating protein-2 (GCAP2) homodimer by stable isotope-labeling, chemical cross-linking and mass spectrometry. J. Am. Soc. Mass. Spectrom. 24, 1969-1979. doi: 10.1007/s13361013-0734-6

Polans, A. S., Buczylko, J., Crabb, J., and Palczewski, K. (1991). A photoreceptor calcium binding protein is recognized by autoantibodies obtained from patients with cancer-associated retinopathy. J. Cell Biol. 112, 981-989. doi: 10.1083/jcb. 112.5.981

Pongs, O., Lindemeier, J., Zhu, X. R., Theil, T., Engelkamp, D., KrahJentgens, D., et al. (1993). Frequenin-a novel calcium-binding protein that modulates synaptic efficacy. Neuron 11, 15-28. doi: 10.1016/0896-6273(93) 90267-u

Ramamurthy, V., Tucker, C., Wilkie, S. E., Daggett, V., Hunt, D. M., and Hurley, J. B. (2001). Interactions within the coiled-coil domain of RetGC-1 guanylyl cyclase are optimized for regulation rather than for high affinity. J. Biol. Chem. 276, 26218-26229. doi: 10.1074/jbc.m010495200

Rätscho, N., Scholten, A., and Koch, K. W. (2009). Expression profiles of three novel sensory guanylate cyclases and guanylate cyclase-activating proteins in the zebrafish retina. Biochim. Biophys. Acta 1793, 1110-1114. doi: 10.1016/j. bbamcr.2008.12.021

Redenti, S., Ripps, H., and Chappell, R. L. (2007). Zinc release at the synaptic terminals of rod photoreceptors. Exp. Eye Res. 85, 580-584. doi: 10.1016/j.exer. 2007.07.017

Semple-Rowland, S. L., Gorczyca, W. A., Buczylko, J., Helekar, B. S., Ruiz, C. C., Subbaraya, I., et al. (1996). Expression of GCAP1 and GCAP2 in the retinal degeneration (rd) mutant chicken retina. FEBS Lett. 385, 47-52. doi: 10.1016/0014-5793(96)00345-6

Sokal, I., Li, N., Surgucheva, I., Warren, M. J., Payne, A. M., Bhattacharya, S. S., et al. (1998). GCAP1 (Y99C) mutant is constitutively active in autosomal dominant cone dystrophy. Mol. Cell 2, 129-133. doi: 10.1016/s10972765(00)80121-5

Stephen, R., Bereta, G., Golczak, M., Palczewski, K., and Sousa, M. C. (2007). Stabilizing function for myristoyl group revealed by the crystal structure of a neuronal calcium sensor, guanylate cyclase-activating protein 1. Structure 15 , 1392-1402. doi: 10.1016/j.str.2007.09.013

Stephen, R., Filipek, S., Palczewski, K., and Sousa, M. C. (2008). $\mathrm{Ca}^{2+}$. dependent regulation of phototransduction. Photochem. Photobiol. 84, 903-910. doi: 10.1111/j.1751-1097.2008.00323.x

Strissel, K. J., Lishko, P. V., Trieu, L. H., Kennedy, M. J., Hurley, J. B., and Arshavsky, V. Y. (2005). Recoverin undergoes light-dependent intracellular translocation in rod photoreceptors. J. Biol. Chem. 280, 29250-29255. doi: $10.1074 / j b c . m 501789200$

Subramanian, L., and Polans, A. S. (2004). Cancer-related diseases of the eye: the role of calcium and calcium-binding proteins. Biochem. Biophys. Res. Commun. 322, 1153-1165. doi: 10.1016/j.bbrc.2004.07.109

Tanaka, T., Ames, J. B., Harvey, T. S., Stryer, L., and Ikura, M. (1995). Sequestration of the membrane-targeting myristoyl group of recoverin in the calcium-free state. Nature 376, 444-447. doi: 10.1038/376444a0

Tang, Q., Liu, Y.-P., Yan, X.-X., and Liang, D.-C. (2014). Structural and functional characterization of Cys4 zinc finger motif in the recombination mediator protein RecR. DNA Repair 24, 10-14. doi: 10.1016/j.dnarep.2014. 09.012

Tzingounis, A. V., Kobayashi, M., Takamatsu, K., and Nicoll, R. A. (2007). Hippocalcin gates the calcium activation of the slow afterhyperpolarization in hippocampal pyramidal cells. Neuron 53, 487-493. doi: 10.1016/j.neuron.2007. 01.011

Weiss, J. L., and Burgoyne, R. D. (2002). "Neuronal calcium sensor proteins," in Handbook of Cell Signaling, (Vol. 2) ed. Bradshaw R. (San Diego: Academic Press), 79-82.

Weiss, J. L., Hui, H., and Burgoyne, R. D. (2010). Neuronal calcium sensor-1 regulation of calcium channels, secretion and neuronal outgrowth. Cell. Mol. Neurobiol. 30, 1283-1292. doi: 10.1007/s10571-010-9588-7

Zernii, E. Y., Komolov, K. E., Permyakov, S. E., Kolpakova, T., Dell'Orco, D., Poetzsch, A., et al. (2011). Involvement of the recoverin C-terminal segment in recognition of the target enzyme rhodopsin kinase. Biochem. J. 435, 441-450. doi: 10.1042/bj20110013

Zernii, E. Y., Nazipova, A. A., Gancharova, O. S., Kazakov, A. S., Serebryakova, M. V., Zinchenko, D. V., et al. (2015). Light-induced disulfide dimerization of recoverin under ex vivo and in vivo conditions. Free Radic. Biol. Med. 83, 283-295. doi: 10.1016/j.freeradbiomed.2015.03.001

Zhao, C. J., Anand, R., and Braunewell, K.-H. (2009a). Nicotine induced $\mathrm{Ca}^{2+}$. myristoyl switch of neuronal $\mathrm{Ca}^{2+}$ sensor VILIP-1 in hippocampal neurons-a possible cross talk mechanism for nicotinic receptors. Cell. Mol. Neurobiol. 29, 273-286. doi: 10.1007/s10571-008-9320-z 
Zhao, C. J., Noack, C., Brackmann, M., Gloveli, T., Maelicke, A., Heinemann, U., et al. (2009b). Neuronal $\mathrm{Ca}^{2+}$ sensor VILIP-1 leads to the upregulation of functional $\alpha 4 \beta 2$ nicotinic acetylcholine receptors in hippocampal neurons. Mol. Cell. Neurosci. 40, 280-292. doi: 10.1016/j.mcn.2008.11.001

Zhao, C., and Braunewell, K. H. (2008). Expression of the neuronal calcium sensor visinin-like protein-1 in the rat hippocampus. Neuroscience 153, 1202-1212. doi: 10.1016/j.neuroscience.2007.10.067

Zozulya, S., and Stryer, L. (1992). Calcium-myristoyl protein switch. Proc. Natl. Acad. Sci. U S A 89, 11569-11573. doi: 10.1073/pnas.89.23. 11569
Conflict of Interest Statement: The author declares that the research was conducted in the absence of any commercial or financial relationships that could be construed as a potential conflict of interest.

Copyright (C) 2018 Ames. This is an open-access article distributed under the terms of the Creative Commons Attribution License (CC BY). The use, distribution or reproduction in other forums is permitted, provided the original author(s) and the copyright owner(s) are credited and that the original publication in this journal is cited, in accordance with accepted academic practice. No use, distribution or reproduction is permitted which does not comply with these terms. 